\title{
Adapting ICAO Language Aspects into Learning Activities in ESP Course Construction for Air Traffic Controller
}

\author{
Laila ROCHMAWATI ${ }^{1}$, MUSTAJI $^{2}$, Siti MASITOH ${ }^{3}$ \\ Civil Aviation Safety Engineering Academy of Surabaya ${ }^{1}$, Language and Literary Post Graduate Program ${ }^{23}$ \\ Universitas Negeri Surabaya \\ Surabaya, Indonesia \\ lailarochmawati@mhs.unesa.ac.id ${ }^{1}$
}

\begin{abstract}
Designing the pattern of the materials English specific purposes for an Aviation English course is the important points. It was shown that they're no synchronized between the learners want and the application on the field. This study discusses integrating language aspects adopted from ICAO for Air Traffic Controller into learning activities in Civil Aviation Safety Engineering Academy of Surabaya. It is intended to develop the configuration of learning activity design specifically for Air Traffic Controller. Model of English Specific Purposes needs analysis is used in this study, which was formulated by Hutchinson \& Waters (1987). The development is presented for learning activities in Civil Aviation Safety Engineering Academy of Surabaya. The questionnaire, aviation English placement test and interview with English teacher were used in this study to obtain the data. Quantitative analysis was carried out using SPSS. This research found the configuration learning activities for the learners using language aspects specified by ICAO. The format of learning activities meets a specific need of the learners. It can be applied for air traffic controller and other learners. The learners can learn aviation English more effectively and apply it for daily activities in the classroom or language laboratory. The future research hopes that the format of learning activities can be applied using e-learning instructional.
\end{abstract}

Keywords: English Specific Purpose, Air Traffic Controller, and ICAO

\section{INTRODUCTION.}

The International Civil Aviation Organisation (ICAO) is a specialized agency of the United Nations, which "sets standards and regulations necessary for aviation safety, security, efficiency and regularity, as well as for aviation environmental protection" (ICAO, n.d.). (Alderson, JC, 2009)[1]. English for specific purposes (ESP) is an approach to language teaching that focuses programmed content on subjects, topic, and issues of direct interest to learners (Doc 9835-AN/453,2004: p. 4-8) [2]. Recently, Indonesia the ESP training, increasing rapidly. This is based on the fact that all businesses and professions require multi-talents who are not only able to speak English, but also understand the knowledge of specific sectors of the profession. ESP training has a function for focusing the trainer what they need to do in English and concentration on the items of the language that they need to undertake a particular task. There are so many fields that ESP tries to guide the learners in a specific way, such as science, technology, medicine, banking, mechanical engineering, and aviation. Aviation context is the specific field in ESP that focusing on the activities, learning, and teaching, language needed in English for aviation. In the aviation world, English has been accepted and actually as a medium of communication. This is mainly applied to airports and international airlines. Indonesia learner who learns English as a foreign language (EFL) are highly motivated, especially on aviation English specific purposes. The number of ESP language teaching, in educational institutions as well as in continuing education is a general impact of increasing the need for English proficiency, the rapid development of fields that use applied linguistics, and improvement in educational psychology. English for specific purposes teaching needs to develop specific aviation English course construction that is different from English as a second language (ESL) teaching. This is because English for specific purposes requires special achievements, students, and specific goals rather than common sector. In the fact, the learner needs a content which is relevant to the interests and work requirements. For the example English for Aviation for Air Traffic Controller course. The aim of the learners learn English for communicating with the same profession as an ATC, the pilot and adjacent unit in the vicinity of the Aerodrome and board successfully. The instructor or the lecturer should give the material content which is related to aviation specific language learning in the class work can focus, on the role-playing (ATC, pilot, adjacent unit), reading, discussing, listening and etc. In order to the 
learner can get maximal input and best opportunity for acquisition of the target language features and encounter every utterance in normal abnormal conditions.

Designing the English language specific aviation English course construction material is essential for the instructor, English for specific purposes (ESP). According to Nunan (1993) [3], a teacher can carry out his duty to develop a strong curriculum material only when given time, expertise, and support. This form of support may be a model and guide for curriculum development and may also take the form of a company (in the aviation context, commonly known, airlines and other companies that are in touch with the aviation industry) requiring consultants capable of providing professional input. Such support should not be viewed independently of a curriculum. Key Issues in the Design of the ESP Curriculum are 1) Improving the ability to communicate with the sector of work 2) balancing the absorption of the content, language and the general language 3) designing appropriate material for groups of students of the same type and different type 4) developing materials (Nunan, 1987: p. 75) [4]. The Aviation English course construction material developed for ATC. It concerns on aviation related aviationmaterial using ICAO English language aspects and relevant to their work. Designing of the ESP related aviation-material using ICAO English language aspects into learning activities in the Civil Aviation Safety Engineering Academy of Surabaya.

Language learning is a complex interaction of a number of factors, involving academic linguistic knowledge, cultural information, and communicative skills (Doc.9835AN/453 2004: 4-11) [1]. Language lecturer or instructor has a role as a trained facilitator to communicate how a language can work effectively, arrange and deliver interesting and engaging the lessons and accurately assess the ability of the learners. Language lecturer or instructor should have professional awareness about how the learner learns a second language, design a class activity who can encourage and enable the learners for interaction with the language. This paper, concerned with the development of the content of the aviation material format and presentation. Adopted a framework from Nation \& Macalister (2010) [5] there are three subprocesses in a model of the parts of the curriculum design process: environment analysis needs analysis and application of principles. The Teaching of English as a Foreign Language (TEFL) has an important history at various levels of education, and the methodology of teaching methods (pedagogy) has been well developed and applied. However, as an English Learning, Teaching activity (ELT), the design of the English for specific purposes (ESP) curriculum needs to be formulated to demonstrate its different characteristics. This study aims to explore a formula to develop English Specific Purpose learning activity design specifically for Air Traffic Controller by adopting ICAO language aspects.

Need analysis is the important step for ESP course. The learner will be more highly motivated in learning about topics and text which are related to their study and work area. Cited in Duddley-Evans and St. John (2009) [6] there are five groups for a conception of need analysis. 1. Target situation analysis and objective needs analysis (e.g. Tasks and activities, learners will use English for; 2. Linguistic analysis, discourse analysis, genre analysis, i.e. knowledge of how language and skills are used in the target situations; 3 . subjective needs analysis, i.e. learners' wants, means, subjective needs-factors that affect the way they learn (e.g. previous learning experiences, reasons for attending the course, expectations) 4. present situation analysis for the purpose of identifying learners' current skills and language use; 5. Means analysis, i.e. information about the environment where the course will run. Stern (1992) [7] argued that there are four types of ESP teaching objectives: proficiency, knowledge, effective and transfer. Proficiency objectives concern to the proficiency of the four language skills: reading, writing, listening and speaking. The substance of knowledge objectives is in the acquisition of linguistic and cultural information. Linguistic knowledge objectives relate to language analysis and awareness of the systematic aspects of language. Cultural knowledge objectives deal with the control of social-cultural rules (mastery of the norms of society, values and orientations and also the ability to recognize culturally significant facts). Affective objectives are about the development of positive feelings toward the subject of study. Transfer objectives concern the ability to generalize from what has been learned in one situation or another. Mumbai, 1978; Hutchinson \& Waters, 1987; Robinson, 1991; Flowerew \& Peacock, 2001; Hamp-Lyons, 2011 in Ling, J; Wang, A \& Zhang, C (2014) [8] said that in quest of better solutions to this issue, the role of needs analysis in any ESP curriculum should not be underestimated. This paper model of ESP needs analysis Hutchinson \& Waters (1987) [9] is used for designing of the ESP related aviation-material. Using ICAO English skill area into learning activities in the Civil Aviation Safety Engineering Academy of Surabaya. The model is illustrated in below.

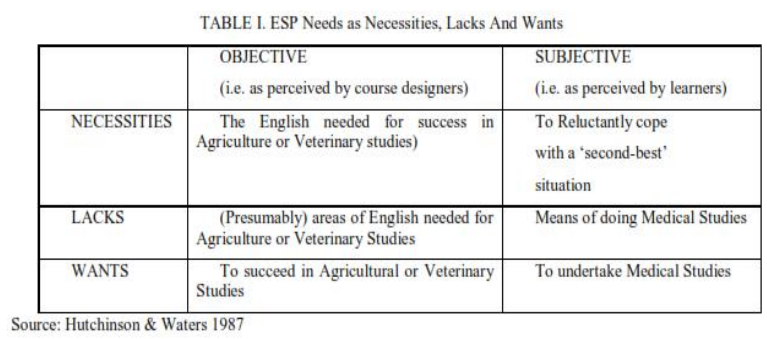

The students can be divided into necessities, lacks and wants. This division can be known in many 
ways: by giving tests; questioning and interviewing; refering to previous performance; ask the leaders, teachers, and anyone involved; collect materials such as reading books and manuals that students must read and analyze, and investigate situations where English will be required by the students. Hutchinson and Waters (1987) [9] explain necessities, lacks and wants as 1. 'Necessities' are the type of needs that is determined by the demands of the target situation, and necessities are what learners need to know so as to function effectively in the target environment.

'Lacks' are the type of needs where the ESP practitioners need to investigate what the learners already know so that the ESP practitioners can decide which necessities the learners lack. 3. 'Wants' are what the learners want to learn. A common problem for learning aviation English is the blankness of designing of the ESP related aviation-material. The lecturer or the instructor requires developing their own design not only based on the learners need and want, but also from the manual document from ICAO (International Civil Aviation Organization).

\section{A. Sample of Research.}

\section{RESEARCH METHOD}

115 students of Civil Aviation Safety Engineering Academy of Surabaya are the sample of this research and fill the research questionnaire. They come from air traffic controller in the first, second and third grade for 2016/2017 academic years.

B. Instrument and Procedures

This research uses some instruments. There are questionnaire, aviation English placement test and interview with the English teacher. The first instrument is used for digging some information from the learners about the proficiency, ICAO language aspects, general English skills area, motivation, and type of English the student wants to learn. It is adapted from Hutchinson, T and Alan W (1994) [10] and David Nunan (2004). [11]

Aviation English placement test is chosen to discover the real proficiency of the learners. The last is an interview with English teacher which focused on the difficulties of the teachers to encounter in all process of learning in their work especially in Aviation English.

\section{FINDINGS AND DISCUSSION}

The result from the English teacher interview shows that the Air Traffic Controller students need some requirements for proficiency in aviation English. There are communicate effectively in voiceonly (telephone/radiotelephone) and in face-to-face situations; communicative on common, concrete, and work-related topics with accuracy and clarity; use appropriate communicative strategies to exchange messages and to recognize and resolve misunderstandings (e.g.to check, confirm or clarify information) in general or work-related context; handle successfully and with relative ease the linguistic challenges presented by a complication or unexpected turn of events that occurs within the context of a routine work situation or communicative task with which they are otherwise familiar; and use a dialect or accent which is intelligible to the aeronautical community (Shawcross, 2011) ).[12]

Based on the questionnaire about proficiency of the student, it can be seen that intermediate is the most student proficiency $(50.4 \%)$. It means that the students not only can understand the core of the complicated recording and reading but also give respond about them. $44.3 \%$ student is classified into advanced. It can be assumed that they understand the content of the recording and reading text that given more. They can react fluently about them. The last proficiency is beginner it consists of $5.2 \%$ students. They can understand the only simple sentences and expressions.

Skills area specified by icao the student to master is interaction, which is $46.1 \%$, for the ICAO skill that they want to improve so much. It can be analyzed that the students think they should be aware that the serenity in the communication between pilots and controllers is very dangerous. They have an opinion when the ATC and pilot communicate, they must be able to understand in every condition even in unexpected communication. The second place is comprehension 27\%. The students, as an ATC, fell that to communicate with the pilot, they have to give clear and accurate information. ATC is not only handle the normal situation but also must be ready for unexpected condition vice versa pilot must understand the instructions from ATC. The third is fluency $16.5 \%$. The students assume communications of air traffic controller (ATC) and the pilot must not only be clear, concise, and unambiguous, but also responses must be delivered efficiently and a rapid response time is expected. The fourth is pronunciation with $7 \%$. Pronunciation plays an important role in helping comprehension between non-native speakers. Vocabulary and grammar have the same rate to wit $1.7 \%$. Relevant terminology, grammatical structures and sentence patterns determined by the function of the language corresponding to the task.

The learners of Civil Aviation Safety Engineering Academy of Surabaya were asked which skill they wanted to improve the most. The result of the analysis indicated that the learners consider that speaking and listening as the most needed to be followed by writing and reading. The students want to improve the speaking skills more than other English skills (51.3\%). They need that skills for communicating with the other ATC, pilot and adjacent unit. They think that speaking is the most important skills for them. The second rating is listening $46.1 \%$ and it is followed by reading and writing. 
The questionnaire about the reason for mastering aviation english shows that working is chosen by the student at the most $(75.7 \%)$. They want to master Aviation English for working at the aerodrome after they learn aviation English in Civil Aviation Safety Engineering Academy of Surabaya.

The students have high motivation for learning aviation English. It can not be found low motivation.

Based on the questionnaire about type of english the students want to learn indicates that aviation English is the most type of English students wanted for learning. The second place is general English. Toefl/toeic is not chosen by the student.

This section discusses the result of environmental analysis. Social and institutional analysis are used for elaborating the reason ESP must use in this academy. Inadequate language ability is one of the factor causes accident and incident. Based on that situation ICAO make a policy that Assembly Resolution A3216 persuade the Council makes effort in a certain direction to the Air Navigation Commission (ANC) leads to a re-review of the ICAO Language requirement for deliberating that condition with a high level of priority and completing a task to strengthen the provisions relating to the use of the English language for radiotelephony communications. 5 March 2008 is the last date that the country under ICAO organization using their own procedure, after that date they must follow the procedure from ICAO for assessing the English ability of flight crew and controllers. Relative facilities for assessing proficiency at the expert level allow for flexibility in assessing judgments. The licensing authority should require a special evaluation (or test) of those who do not demonstrate expert skill. Phraseology trials are not appropriate. Demonstration of speaking and listening skills is actually needed. Indonesia educational policy recently makes English is one of the languages most supported by the ministry of education. The supportive laboratory has already existed in this Civil Aviation Safety Engineering Academy of Surabaya. It consists the modern infrastructure and other facilities. Aviation English material for air traffic controller may consist of aeronautical communicative language functions a list of language functions commonly used by controllers and pilots in the course of their work; Inventory of events and domains an inventory of events and related domains which characterize the routine and non-routine dayto-day work of controllers and pilots; List of priority lexical domains a list of lexical domains which are most pertinent to the communicative needs of controllers and pilots; List of language tasks, a list of common language tasks performed by controllers based on an extensive needs analysis of controller communicative tasks; and List of common, English four-word clusters applied to aviation communications.(Doc.9835AN/453 2004) [1].
The questionnaire, placement test, interview, and observation have been done in this research. The result shows that the lecturers or instructors should develop their own design not only based on the learners need and want but also from the manual document from ICAO (International Civil Aviation Organization). The learners would like to improve their skill in general English and skills area specified by ICAO. There must be some interesting topics for the learners to improve their communicating skills in aviation English. Based on the need and environmental analysis this study creates a design which is adapted from ICAO language aspects and apply in learning activities in ESP course construction for Air Traffic Controller (ATC) in Civil Aviation Safety Engineering Academy of Surabaya.

This design contains four skills (listening, speaking, reading and writing) in general English combine six language aspects (vocabulary, grammar, pronunciation, fluency, comprehension, and interaction) specified by ICAO. Each column contains aviation English materials that comes from English for Aviation for Pilots and Air Traffic Controllers by Oxford University Press[13]. Zolfagharian, A., \& Khalilpour, J. (2015) [14] argued English for Aviation for Pilots and Air Traffic Controllers is analyzed and evaluated as suitable book for both purposes of classroom book and selfstudy. Notwithstanding some weaknesses, the book can satisfy the needs and interests of students whom are pilots and air traffic controllers to do their job with the first goal of safety. It covers all the learners need for steeping aviation English. In the other side, Khosravany Fard,Hamid (2014) [15] discussed another textbooks. The tittled Aviation English for ICAO (international civil aviation organization) compliance by Macmillan publications [16]. The results suggested that Aviation English follows a topical and functional syllabus aiming at improving aviators' speaking and listening skills. Moreover, this ESP book integrates interactive activities in all parts of its units (pronunciation,vocabulary, and functions). It means the text book hasn't completed yet since only consist of two language skill speaking and listening lack of reading and writing. it is composed only pronunciation, vocabulary, and functions less of comprehension and interaction. The table shows listening is the first place in the table. It is in accordance with the questionnaire from the learners that they most need is listening. This study tries to fill the table with the compatible aviation English material for the vocabulary the lectures give the instruction to the learners for listening twice and ticking the words that they hear on the worksheet and finding words or phrase in the exchange with have same meaning; for the grammar they listen and write that they hear and put the words in the right order to make questions; for fluency the learner listen to five 
exchanges and write the number of the exchange next to the description on their worksheet, tick how often they expect to hear each of these in their work, the last they discuss the answer with a partner or listen to the exchange as a long haul flight approaches its destination then answer the questions; for pronunciation learners listen and repeat the ICAO and alphabet and number and listen to the sample message and repeat; for comprehension the learners give the subject about air communications are vital for safety of air travel then listen to the two exchanges and answer the question; and the last for interaction learners work with a partner to pass and record messages, if they aren't sure about the message, ask for clarification then repeat say again until have understood. Listening is very important for the Air Traffic Controller learners. Based on the interview result they fell that the most activities in their job are listening and speaking. Therefore the second place in that table above is speaking. Fluency is the main focus in it since the pilot and other partners of ATC demand it whether in normal Moreover in an abnormal situation. The study gives instructions for the learners to respond the topic about the emergency situation and they have to answer the question what would you do in that situation after that they compare their answer to the partners. The third is writing. There is a difference of perception from the lectures point of view and the learners. The lectures interview result show that writing is more important than reading since the ATC must write down all the information related to airplane movement thus it put the third place after speaking. For writing, the learners match the two parts of the sentences to make six reasons about the topic why international communications may be difficult and answer the question on their worksheet. The last place is reading. The learner's activities to improve their vocabulary to expedite their fluency by underline the plain English phrases in their workbook, then answer the questions for each exchange. Although reading in the last position, it is also important for the learner. Cited by Adamski \& Stahl (1997) [17] nevertheless, the effectiveness and the usefulness of a message depend not only on the information it contains, but also on message design, reader perception, and reader understanding. It means that the reader's opinian and cognition influence how the meaning of text.

\section{CONCLUSIONS AND SUGGESTIONS}

There many materials from aviation English that the lecturers can put on that table. They just follow the pattern from it. Lecturers should give the learners a textbook and bring the learners interesting instruction such as role-playing, group discussion, and independent work. Those tactics encourage the learners more active to improve their ability. The lecturers can search the supplementary material about aviation by using materials from general aviation training text for pilot or ATC or mechanics; getting the core and try to rewrite using the own word for language training; adopting some articles from magazines with contain specific topic about aviation and modifying for language utilization or use the original one. Finding the newest video concern on aviation aspect from youtube, DVD, CD or another source; getting a brochure from aviation equipment supplier try to contact them via email to get hundreds of titles on aviation subjects and provide excellent preparation materials for teachers entering the ESP aviation field. They can also be edited and graded to provide ideal class text.

For the conclusion, it is better for the lecturer or the instructor to develop designing of the ESP related aviation-material based on their specific needs of the learners. The first step by analyzing the need and the environment of the learners. The lecturer can observe the language ability of the learner for knowing what skills they need, what type of language they already know, what type of language they lack. They should focus on the way they teach, whom they teach, how to deliver the learners' goals and motivations. By designing learning activities which are adapting from ICAO language aspects can improve the teaching and learning of the language for specific purposes especially aviation English for Air Traffic Controller (ATC).

\section{REFERENCES}

[1] Alderson, J. C. The politics of Aviation English testing. Language Assessment Quarterly, 8 (4), 386-403; 2011. DOI: 10.1080/15434303.2011.622017

[2] ICAO. Manual on the Implementation of the language proficiency requirements (Doc 9835-AN/453). Montréal, Canada: International Civil Aviation Organization; 2004.

[3] Nunan David. Research Method In Language Learning, Cambridge: Cambridge University Press;1993.

[4] Nunan, David. Designing Task for the Communicative Classroom. Cambridge: Cambridge University Press; 1989

[5] Nation, I. S. P. \& John Macalister. Language Curriculum Design. New York \& London: Routledge, 2010.

[6] Duddley-Evans, T., and M.J.St John, Development in English for Specific Purposes: A Multidisciplinary Approach, Cambridge: CUP; 2009.

[7] Stern, H. H. Issues and options in language teaching, Oxford: Oxford University Press; 1992. 
[8] Lin, J. et al. Integrating Curriculum Design Theory into ESP Course Construction: Aviation English for Aircraft Engineering. Open Journal of Modern Linguistics, 4, 219227.

http://dx.doi.org/10.4236/ojml.2014.42017; 2014.

[9] Hutchinson $\mathrm{T}$ \& Waters A. English for specific purposes.New York: Cambridge University Press; 1987.

[10] Hutchinson, T and Alan W. English for Specific Purposes. A learning-centered approach. Cambridge: Cambridge University Press; 1994.

[11] Nunan, David. Task-Based Language Teaching. Cambridge University Press. UK; 2004.

[12] Shawcross, P. Flightpath: Aviation English for Pilots and ATCOS. Cambridge, UK: CUP; 2011.

[13] Zolfagharian, A., \& Khalilpour, J. Evaluation and content analysis of "English for Aviation for pilots and air traffic controllers" textbook as an ESP book. International Journal of Language Learning and Applied Linguistics World, 8 (2), 36-50; 2015.

[14] Khosravany Fard, H., Khosravany Fard, H., Khosravany Fard, A., \& Baghi, B.A. An analytical evaluation of Aviation English textbook. International Journal of Research Studies in Language Learning, 4 (1), 61-70; 2015.

[15] Emery, H., \& Roberts, A. Aviation English for ICAO compliance. Macmillan;2008.

[16] Adamski, A. J., \& Stahl, A. F. Principles of design and display for aviation technical messages. Flight Safety Digest, 16 (1), 1-29; 1997. 